\title{
Circadian patterns in the activity of the Brazilian cave cricket Strinatia brevipennis (Ensifera: Phalangopsidae)
}

\author{
SONIA HOENEN \\ Departamento de Zoologia, Instituto de Biociências, Universidade de São Paulo, Rua do Matão, trav. 14, n. 101, 05508-090, São \\ Paulo, SP, Brasil; e-mail: smhoenen@ib.usp.br
}

Keywords. Ensifera, Phalangopsidae, Strinatia brevipennis, cave crickets, circadian rhythms, masking, entrainment, plasticity

\begin{abstract}
This paper presents data on the activity rhythms of the Brazilian cave cricket, Strinatia brevipennis. Recordings were made in the laboratory in a sound-proof constant environment. Recordings were made either under constant darkness or LD cycles, with food provided ad libitum or not, and with crickets isolated or with a conspecific near the cage. Some crickets were tested with pulses of sound. Raw data are presented in the form of single plot actograms and analyzed using the phase weighted stack (PWS) method. These cave crickets showed a somewhat erratic patterns of activity, although a circadian component could be detected. All the environmental variants tested (food availability, presence of conspecific and sound pulses) seemed to mask any activity rhythm indicating they are possibly important in determining the temporal organization of these crickets. Their activity patterns are discussed in terms of the plasticity of a cave animal's circadian system.
\end{abstract}

\section{INTRODUCTION}

The cave habitat is characterized by stable physical features and a patchy and low availability of food) (Gnaspini \& Hoenen, 1999). Animals living in caves range from species that need to leave caves periodically (trogloxenes) to those that are confined to these subterranean environments (troglobites) (Holsinger \& Culver, 1988). There are also troglophilic species, which include some populations that complete their life-cycles entirely inside the subterranean environment, and others that live outside, but with some individuals moving between these environments.

Troglobitic animals may have modifications, called troglomorphisms, like the enhancement of non-visual sensory modalities and appendages, smaller eyes and reduced pigmentation. Troglomorphisms are generally related to the absence of light and consequent reduction in the availability of food. In response to the low availability of food, selection favours a reduced metabolism.

Among the metabolic mechanisms, one of the most conspicuous differences between troglobitic and epigean species is in their endogenous biological rhythms. A biological clock enables organisms to anticipate temporal changes in the environment and thus confers the property of being temporally adapted (Page, 1989; Marques \& Waterhouse, 1994). In trogloxene species, the presence and synchronization of endogenous rhythms enables them to adjust their exits and returns to a cave to appropriate epigean times. In contrast, it is generally accepted that troglobites lack internal clocks (Lamprecht \& Weber, 1991). However, one would expect troglophiles to show clear circadian patterns since these species have populations living in epigean environments.

Although endogenous biological rhythms are selfsustaining (Bünning, 1960) they are synchronized (or entrained) by environmental cycles, called Zeitgebers (Aschoff, 1960), which guarantee the proper temporal adjustment to the environment. For the majority of the species that live above ground, the light/dark cycle is the main Zeitgeber (Aschoff, 1960). However, for those species that live in permanently dark habitats, other cycles could entrain the biological rhythms such as high/low temperature cycles, high/low humidity cycles, social effects, cycles in food availability, etc. (Moore-Ede et al., 1982; Hoenen \& Marques, 2000).

On the other hand, the expression of an entrained rhythm could be masked. The masking will depend on the nature and intensity of the stimulus, as well as on the sensitivity of the organism (Aschoff, 1960, 1988). The same factors that, as cycles, act as Zeitgebers, may act as masking agents. Therefore, biotic factors (e.g., social stimuli, presence of sexual patterns, presence of predators) may modify overt rhythms, as shown in crickets (Loher, 1979) and hamsters (Aschoff \& von Goetz, 1988). One recent field example of probable masking by food needs was described in the cave harvestman Goniosoma spelaeum (Gnaspini et al., 2003).

There are several species of cricket that have colonized the cave environment. Strinatia brevipennis is a nocturnal, non-singing cricket, living in caves in southeastern Brazil. These crickets feed inside the caves (on debris, carcasses, bat guano, etc.); they have well developed eyes, long antennae and legs, with a tympanum in the fore tibia (Hoenen \& Marques, 1998; Gnaspini \& Hoenen, 1999). Although it lives mainly in caves, this species has a disjunct distribution, inhabiting several noninterconnected caves and therefore should be considered a troglophile. However, it has a strong relationship with caves, characteristic of a "strict" troglophile, as defined by Gnaspini \& Hoenen, 1999. In some populations individuals do not leave the cave and young instars can be found very deep in the caves (Gnaspini \& Hoenen, 1999). 
Because it is a troglophilic species, one would expect it to show clear circadian patterns. Field studies conducted on this species detected a daily rhythm in movements within the caves: the crickets migrate inwards during the day, resting deep inside the cave; and move towards the entrance at night (Hoenen \& Marques, 1998).

This paper presents data on the activity rhythms recorded in the laboratory under several conditions with the aim of detecting and analysing the circadian components. The patterns are discussed focusing on the plasticity of the circadian systems of cave animals.

\section{MATERIAL AND METHODS}

Adult male and female crickets (Strinatia brevipennis, Phalangopsidae) were collected in caves in the Parque Estadual Intervales in southeastern São Paulo state. Individuals were kept together in constant darkness, in a room located in the basement of a building, where the temperature was $20^{\circ} \mathrm{C} \pm 2^{\circ} \mathrm{C}$ and humidity ca $80 \%$. Crickets were fed twice a week with fresh vegetables. Only adult crickets were studied. Before the tests, crickets were kept isolated in a Styrofoam box, without food for 3 days. For the tests, the animals were transferred to an actograph illuminated by red light ( $680 \mathrm{~nm}$, ca 10 lux).

The activity was recorded in an actograph, which detects the vibration produced when the crickets move. The system detects all vibratory movements transferred to the walls of the cage in which the cricket is placed and thus records all body movements of the animal. The vibrations were detected by acoustic sensors (accelerometers) connected to the walls, which sends electric signals to a decoding system. The vibratory message is amplified and the signal compared to a $50 \mathrm{mV}$ threshold. If the signal is higher, it is treated as a vibration and recorded. Every tenth of a second this information is passed to a computer via a specific program. This time series was averaged over 1 min intervals. A full description of the system is presented in Hoenen \& Gnaspini (1999).

The crickets were tested in a sound-proof environment (inside a sterilizer turned-off), at a constant temperature $\left(20^{\circ} \mathrm{C} \pm 1{ }^{\circ} \mathrm{C}\right)$ and a humidity high enough to prevent the cricket dying of dessication (ca 90\%). Several tests were performed: either under constant darkness (dark means red light) or LD cycles (a ca 15 lux light intensity was provided by a white-bulb lamp), with food provided ad libitum or not, isolated or with a conspecific

TABLE 1. Conditions of the tests performed using Strinatia brevipennis and sample sizes. Some of the crickets experienced more than one condition during the same test record. The numbers in parentheses and marked with an "*" indicate tests in which no circadian periodicity was detected.

\begin{tabular}{ll}
\hline Condition of the test & Crickets tested \\
\hline 11L $: 13 \mathrm{D}-\mathrm{L}: 7 \mathrm{~h}$ to $18 \mathrm{~h}$ & $4 \%\left(1^{*}\right)$ \\
& $3 \sigma^{*}$ \\
DD (with ad libitum food) & $5 \%\left(2^{*}\right)$ \\
& $5 \sigma^{*}\left(1^{*}\right)$ \\
& $6 \%\left(1^{*}\right)$ \\
DD + without food & $5 \sigma^{*}\left(1^{*}\right)$ \\
& $2 \%$ \\
DD + conspecific & $4 \sigma^{*}\left(1^{*}\right)$ \\
& $1 \%$ \\
DD (without sound isolation) & $2 \sigma^{*}$ \\
& $1 \%$ \\
DD + sound pulses & $2 \sigma^{*}\left(1^{*}\right)$
\end{tabular}

near the cage (see Table 1 for details and sample sizes). When food was provided, it was renewed every 5 days. Some crickets were tested with pulses of sound, presented in 4 consecutive days, starting at 10:00 h (clock hour). The pulses consisted of 30 min of sound (a song of ca $80 \mathrm{~dB}$ ) followed by $30 \mathrm{~min}$ of silence, which was repeated 3 times each day. Hence, the pulses occurred from 10:00 to 10:30, 11:00 to $11: 30$ and 12:00 to $12: 30$ h. Although several tests were performed (see Table 1) only the most representative record for each condition is used as an illustration of the features detected.

The data is presented in single plot actograms and analyzed using the phase weighted stack (PWS) method, which is a noisereduction method that detects weak but coherent signals through a weighted summation of the data. A full description of the method and its application in chronobiological research are presented elsewhere (Schimmel \& Paulssen, 1997; Hoenen et al., 2001). In short, the first step is a linear summation of the raw data, considering different periodicities. The result is a linear stack (LS), that still shows the influence of high amplitude nonperiodical signals. The second step is a summation of the raw data considering their coherence, regardless of their amplitude, resulting in a phase stack (PS). The final step is the PWS, that combines the information of LS and PS, resulting in a stack from which the incoherent noise has been eliminated, allowing the detection of weak signals that would otherwise be indistinguishable from the background noise.

This method was chosen because the activity records observed had an intricate pattern of small peaks, interspersed with rarer ones of much higher amplitude. Attempts to analyze this data with the usual methods gave inconsistent results and sometimes did not detect rhythms.

\section{RESULTS}

A persistent circadian component was detected in all tests (see Table 2 and Figs 1-6), indicating the presence of an endogenous clock in $S$. brevipennis. Although a cir-

TABLE 2. Periodicities detected by the PWS method in some of the activity records of Strinatia brevipennis.

\begin{tabular}{lccc}
\hline \multirow{2}{*}{ Dates } & $\begin{array}{c}\text { Condition } \\
\text { of the test }\end{array}$ & $\begin{array}{c}\text { Frequency } \\
\text { detected (h) }\end{array}$ & in Fig. \# \\
\hline \multirow{3}{*}{ January / 98 } & 11L : 13D & $22: 50$ & \\
& & $24: 00$ & 1 \\
September / 98 & DD & $24: 14$ & \\
& DD + female & $23: 44$ & 2 \\
June / 98 & DD + ad libitum & $25: 00$ & 3 \\
November / 98 & DD + without food & $24: 00$ & 4 \\
February / 99 & DD + without food & $24: 45$ & 5 \\
& DD + with food & $23: 48$ & \\
& DD + without food & $22: 30$ & \\
& DD + ad libitum & $23: 56$ & \multirow{2}{*}{6} \\
July / 98 & food & $24: 04$ & \\
& & $23: 42$ & 7 \\
December/ 99 & DD + without food & $22: 51$ & \\
& DD + with food & $23: 18$ & \\
& DD + without food & $24: 15$ & \\
& (before sound pulses) & $24: 24$ & \\
& & $22: 06$ & \\
& DD + sound pulses & $22: 30$ & \\
& & & \\
& &
\end{tabular}




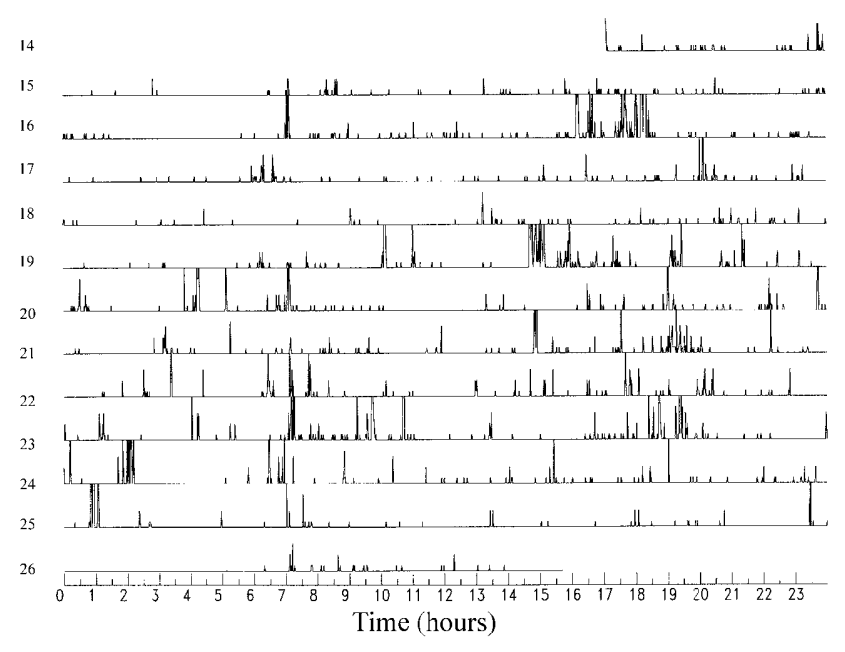

Fig. 1. Single plot of the locomotor activity of a female Strinatia brevipennis cricket, recorded between 14th to 26th January, 1998, in 11L : 13D (lights-on at 07:00 h).

cadian component could be detected in constant conditions [e.g., Figs 2 (first part), 3 and 6 (first part)], these cave crickets had an erratic pattern of activity.

Fig. 1 shows the activity of a female cricket, recorded for 13 days, under $11 \mathrm{~L}$ : 13D - lights came on at 07:00 h. Although there was an initial reaction to the light, there was no clear synchronization of the rhythm and the analysis detected other frequencies in addition to a $24 \mathrm{~h}$ one (see Table 2).

The presence of another individual clearly altered the activity pattern. For instance, Fig. 2 shows the activity of a male cricket recorded for 22 days, in constant darkness (DD). During the first seven days, the male was alone and showed a cyclic pattern with a period longer than $24 \mathrm{~h}$ (24 h 44). From the $8^{\text {th }}$ day onward, a female cricket was placed near the male's test cage. There was a clear intensification of activity after the introduction of the female, and the periodicity was less than $24 \mathrm{~h}(23 \mathrm{~h} 10)$ (Table 2).

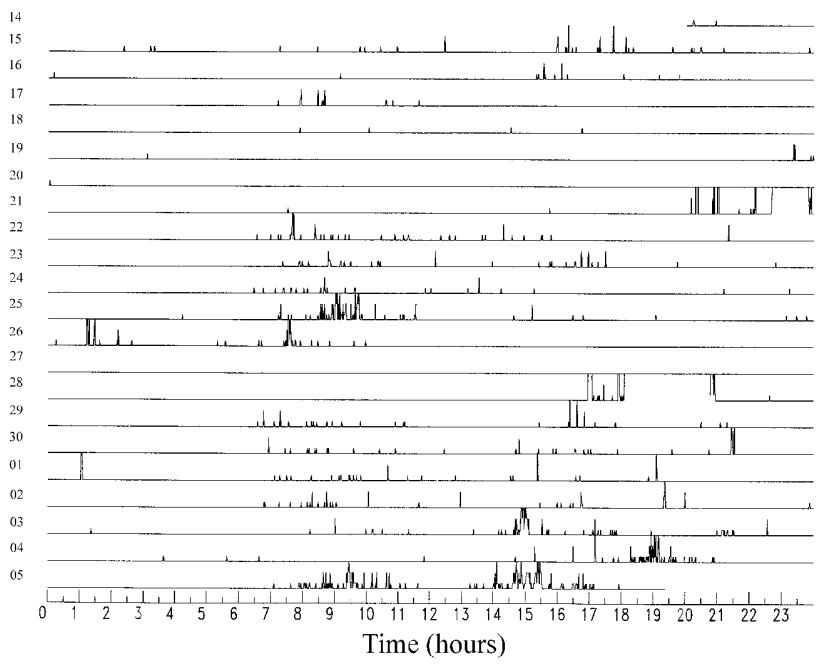

Fig. 2. Single plot of the locomotor activity of a male Strinatia brevipennis cricket, recorded between September 14th to October 5th, 1998, in DD. Female present from day 8 onwards.

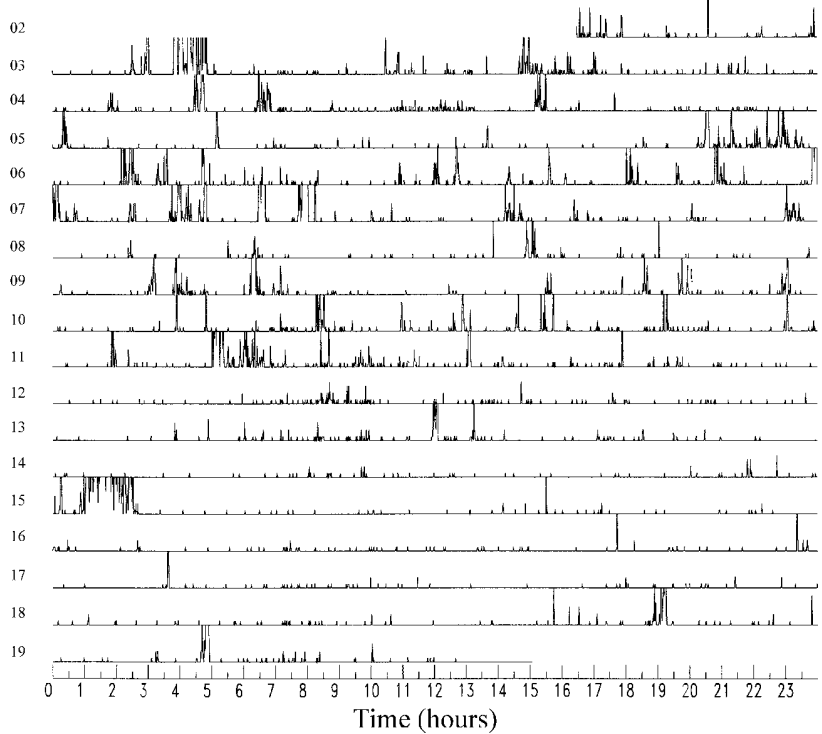

Fig. 3. Single plot of the locomotor activity of a female Strinatia brevipennis cricket, recorded between 2nd to 19th June, 1998, in DD with ad libitum food.

Food also affected the crickets' activity pattern. It is known that food can act as a Zeitgeber in some species, and modulate the rhythm in others. When these cave crickets were kept "without food" for several days the periodicity became more clearly $24 \mathrm{~h}$. For instance, compare Fig. 3 (a female cricket kept in DD with ad libitum food for 18 days) and 4 (a female cricket kept in DD without food for 12 days). In addition, the periodicity shown by the cricket with food (Fig. 3) was $25 \mathrm{~h}$, in contrast to the $24 \mathrm{~h}$ for the cricket without food (Fig. 4).

The possible masking effect of hunger is seen even in the same cricket (e.g., Fig. 5). This figure represents the activity of a female cricket kept in DD without food for 8 days, then with food for 8 days and again without food for 5 days. A more intense activity pattern is apparent during the first 8 days, when the cricket was starving

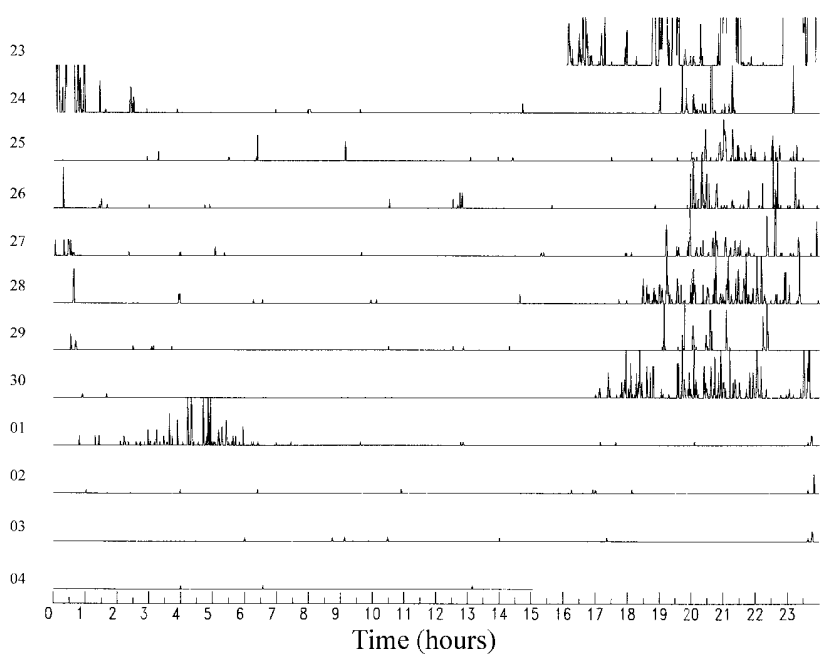

Fig. 4. Single plot of the locomotor activity of a female Strinatia brevipennis cricket, recorded between November 23rd to December 4th, 1998, in DD/without food. 


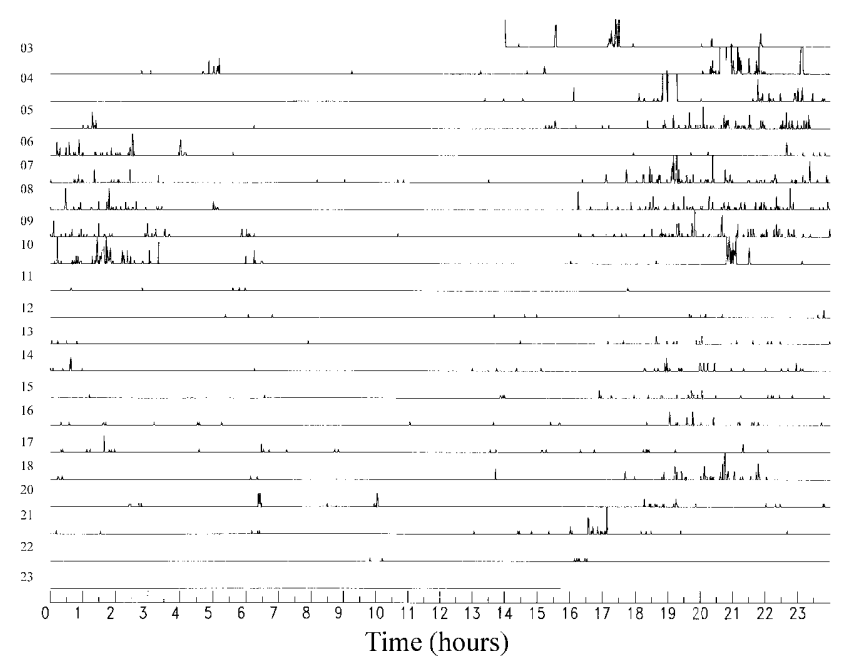

Fig. 5. Single plot of the locomotor activity of a female Strinatia brevipennis cricket, recorded between 3rd to 23rd February, 1999. From 3rd to 10th day $=\mathrm{DD} /$ without food; from 11th to 19 th day $=\mathrm{DD} /$ ad libitum food; from 20th to 23 rd day $=$ $\mathrm{DD} /$ without food.

(considering it had no food in the previous 3 days). After food was offered, the attenuation of the activity was marked. It is noteworthy that the periodicity when detected for the starved was more than $24 \mathrm{~h}(24 \mathrm{~h} \mathrm{45)}$ but when supplied with food it was less than $24 \mathrm{~h}$, even during the second interval "without food" (22 h 30). Perhaps the second interval was too short for the cricket to become hungry again after feeding for 8 days.

Besides hunger and presence of conspecifics, sound is also a strong masking factor. For instance, the activity of crickets kept in constant conditions increased when exposed to human noise, with a marked intensification between 08:00 and 18:00 h (see Fig. 6). The days with only a few movements were at the weekend's. Thus, the crickets followed the daily and weekly pattern of human activity in the building. As this influence could represent

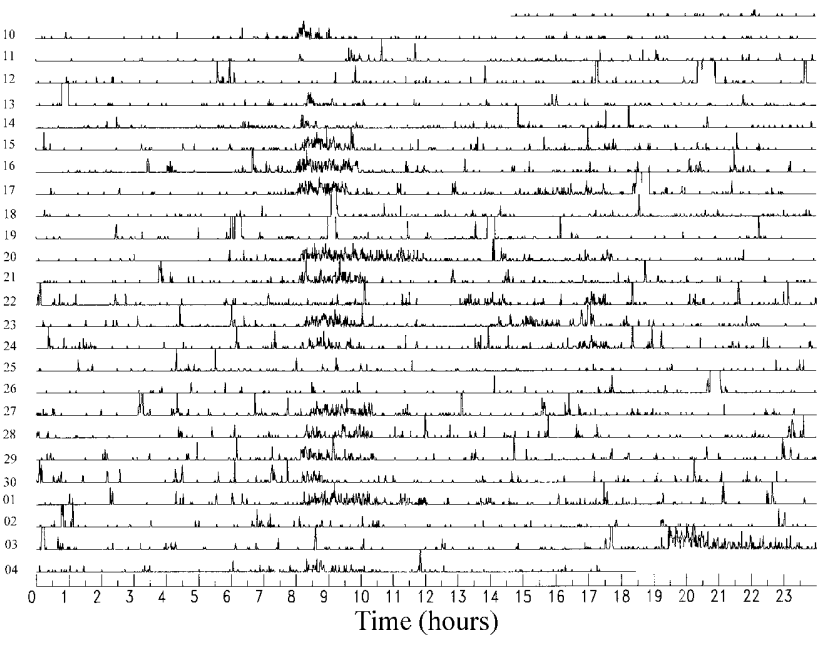

Fig. 6. Single plot of the locomotor activity of a male Strinatia brevipennis cricket, recorded between July 10th to August 4th, 1998, in DD with ad libitum food.

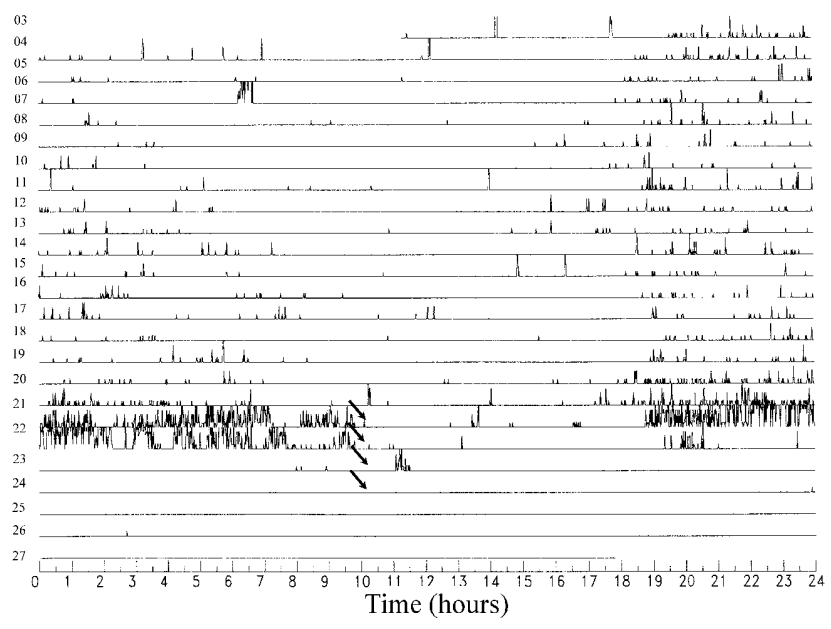

Fig. 7. Single plot of the locomotor activity of a male Strinatia brevipennis cricket, recorded between 3rd to 27th December, 1999. From 3rd to 12 th day $=\mathrm{DD} /$ without food; from 13 to 17 th day $=\mathrm{DD} /$ ad libitum food; from 17 to 27 th day $=$ $\mathrm{DD} /$ without food, but from 20th to $23 \mathrm{rd}$ day $=$ sound pulses. The beginning of the pulses on each day are marked by arrows.

either entrainment or masking, some animals were tested using sound pulses in constant conditions. The result, shown in Fig. 7, suggests a masking effect. This actogram represents the activity of a male cricket submitted to pulses of sound, starting on day 17 (marked by arrows on the figure). There was a marked intensification of activity on these days. However, there was a prompt suppression of activity during the pulse and activity was only restored several hours after the last pulse $(12: 30 \mathrm{~h})$. In the following 3 days, activity commenced progressively later each day, suggesting a free-run. Another very intriguing feature was the absence of activity after this manipulation. The pre-pulse period was more than $24 \mathrm{~h}$

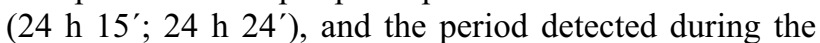
pulse treatment was less than $24 \mathrm{~h}\left(22 \mathrm{~h} 06^{\prime} ; 22 \mathrm{~h} 30^{\prime}\right)$.

Therefore, food availability, presence of a conspecific and noise seemed to act as masking agents.

\section{DISCUSSION AND CONCLUSIONS}

The detection of circadian frequencies in free-running rhythms in locomotor activity suggests the presence of an endogenous circadian component. However, because these crickets seem to remain motionless for very long periods of time, the rhythmic pattern is far from clear. In addition, the activity patterns recorded may have been masked, which leads to speculations about the importance of masking for cave animals.

Bearing in mind the restrictive nature of the cave environment, the laboratory conditions, with ad libitum food and constant temperature and humidity, could have acted as negative masking agents, suppressing activity. This is supported by the observations that crickets not supplied with food showed clearer rhythms (see Figs 4-5). The absence of food may have forced the crickets to forage and they did so following an endogenous circadian timing. 
Although unusual, sound also seemed to affect the activity patterns of $S$. brevipennis crickets. The influence of sound on the biological clock has been studied in birds and mammals. Cycles of sound and silence can entrain (Menaker \& Eskin, 1966) or act as a weak Zeitgeber in birds (Enright, 1965; Lohmann \& Enright, 1967). In mammals, on the other hand, artificial noise masks the food intake pattern of rabbits (Bobbert \& Zwart, 1988) and has no effect on the activity rhythm of rats (Vilaplana et al., 1995).

Usually tests involving sound are performed with the aim of entraining a rhythm (Menaker \& Eskin, 1966; Moeller et al., 1992; Vilaplana et al., 1995) and only a few with the possibility of masking (e.g. Menaker \& Eskin, 1966). In order to exclude the possibility of masking, it must be shown that the phase of the rhythm is shifted during entrainment, i.e., the free-running period of the organism after a sound pulse must show a phase shifting. However, in the tests performed on S. brevipennis crickets, there was no activity recorded after the 4-days series of sound pulses, thus it was not possible to conclude whether it was entrainment or masking, although masking was the more likely (see Fig. 7).

Human noise may influence biological rhythms in experimental animals. For instance, the activity pattern of the Mongolian gerbil, Meriones unguiculatus, is highly influenced by human activity outside the test-room, indicating a high sensitivity to external factors (Klaus et al., 2000). The authors did not comment on whether the pattern was entrained or masked. A similar clear reaction to human noise was recorded for $S$. brevipennis crickets tested in a room without sound isolation (see Fig. 6).

In addition to activity, respirometric studies on this species (unpublished results) show no clear circadian oscillation in the consumption of oxygen. That is, the respiratory and locomotor activities are similar. Moreover, the behavioural repertoire of the crickets seem to be very limited (Hoenen \& Marques, 1998). As the crickets were motionless most of the time they had low respiratory rates, which hinders the detection of clear circadian patterns (in both activity and oxygen consumption). Ahearn \& Howarth (1982) were also unable to detect a daily rhythm in the metabolic rate of the troglobitic cricket Caconemobius varius, however, an epigean species (Caconemobius fori) showed a clear rhythm, with higher oxygen consumption at night (Ahearn \& Howarth, 1982).

The reduced overt rhythm in the troglophilic cave crickets Strinatia brevipennis could be a modified rhythmic expression similar to that recorded in troglobitic animals (Ahearn \& Howarth, 1982; see also Lamprecht \& Weber, 1991 and Gnaspini \& Hoenen, 1999). This is particularly intriguing since troglomorphic reductions are not expected in epigean and non-troglobitic species which are subjected to daily variations.

Troglomorphisms are generally associated with a reduction in food availability. As a response to low food availability selection might favour reduced metabolism, which results in reduced rhythms. Alternatively, reduced rhythms may mitigate the effects of an unpredictable environment (i.e., they are active only when necessary). However, species that are able to colonize the hypogean environment may already possess characters that facilitate this colonization - preaptations (e.g. the use of non-visual sensory modalities and a low metabolism) (Gnaspini \& Hoenen, 1999). Therefore, the weak activity pattern detected in Strinatia brevipennis could be a preaptation and not a troglomorphism.

If it were a preaptation, the erratic activity pattern observed evolved prior to cave colonization. In caves, the absence of a rigid endogenous rhythm may be advantageous because it allows flexibility in temporal organization. This flexibility may be favoured by the unpredictability of the cave habitat. On the other hand, the overt rhythm of epigean populations could be corrected by means of a direct response to the LD cycle (masking), avoiding the risks of mistaken entrainment.

Redlin \& Mrosovski (1999b) showed that the direct effect of light could substitute for the endogenous control of the circadian clock in the activity of hamsters. Their results, together with those described for SCN-lesioned chipmunks (De Coursey et al., 2000), support the idea of Aschoff (1960) that masking complements the endogenously controlled output from the clock. Hamsters showed a strong but adjustable masking response to light, which restricted the endogenous activity to an appropriate time (Redlin \& Mrosovski, 1999a).

The reason for the activity patterns shown by $S$. brevipennis is not obvious. On the one hand, the free-running rhythms are weak, as well as the entrainment to LD cycles. On the other hand, the marked masking is possibly a way of organizing rhythmic expression, which is consistent with the extreme conditions of the subterranean environment. It is because of masking that an organism can react to an environmental stimulus in a different phase than the one established by entrainment (Aschoff, 1988). This mechanism facilitates, for instance, the utilization of an unexpected food source, response to an available sexual partner, or even escape from a predator, among other reactions, all of them important for the survival of an individual and the preservation of the species. It is because of this plasticity that cave animals can cope with the subtle events of cave habitats, which are more peculiar and often more extreme than epigean environments.

In conclusion, the results of this study have stimulated speculations about the evolution of circadian components when the selection pressure associated with high amplitude environmental cycles is relaxed. One possibility is that masking mechanisms are even more important than entrainment for cave animals. The main evidence for this is the lack of entrainment to LD cycles of pigmented species with well developed eyes. This study also showed that it is difficult to generalize about physiology and behaviour of non-troglobitic animals, especially troglophiles (see also Gnaspini \& Hoenen, 1999). Therefore, for a better understanding of the evolution in subterranean environments more studies on these animals are needed.

ACKNOWLEDGEMENTS. The author is indebted to M.D. Marques, supervisor of this Ph.D. study, and to P. Gnaspini for 
the revision and helpful suggestions on the manuscript. This study was supported by grant \# 96/2494-3 from FAPESP (Fundação de Amparo à Pesquisa do Estado de São Paulo).

\section{REFERENCES}

Ahearn G.A. \& Howarth F.G. 1982: Physiology of cave arthropods in Hawaii. J. Exp. Zool. 222: 227-238.

Aschoff J. 1960: Exogenous and endogenous components in circadian rhythms. In Cold Spring Harbor Symposia on Quantitative Biology 25. Long Island Biological Association, New York, pp. 11-28.

Aschoff J. 1988: Masking of circadian rhythms by Zeitgebers as opposed to entrainment. Adv. Biosci. Trends Chronobiol. 73: $149-161$.

Aschoff J. \& von Goetz C. 1988: Masking of circadian activity rhythms in male golden hamsters by the presence of females. Behav. Ecol. Sociobiol. 22: 409-412.

Bobbert A.C. \& ZWARt R.J.M.G. 1988: Analysis of the effects of some factors influencing the rabbit's food intake pattern. I. Modification of the circadian pattern by the retinal maintained discharge. II. Entrainment of the rhythm by 24-h LD alternations. III. Masking by low-frequency noise. J. Inter. Cycle Res. 19: 257-274.

BüNNING E. 1960: Circadian rhythms and the time measurement in photoperiodism. In Cold Spring Harbor Symposia on Quantitative Biology 25. Long Island Biological Association, New York, pp. 249-256.

De Coursey P.J., Walker J.K. \& Smith S.A. 2000: A circadian pacemaker in free-living chipmunks: essential for survival? $J$. Com. Physiol. (A) 186: 169-180.

ENRIGHT J.T. 1965: Synchronization and ranges of entrainment. In Aschoff J. (ed.): Circadian Clocks. North-Holland, Amsterdam, pp. 112-124.

Gnaspini P. \& Hoenen S. 1999: Considerations about the troglophilic habit: the cave cricket model. Mém. Biospéol. 26: 151-158.

Gnaspini P., Santos F.H. \& Hoenen S. 2003: The occurrence of different phase angles between contrasting seasons in the activity patterns of the cave harvestman Goniosoma spelaeum (Arachnida, Opiliones). Biol. Rhythm. Res. 34: 31-49.

Hoenen S. \& Gnaspini P. 1999: A new system for recording endogenous activity rhythms of cave arthropods. Mém. Biospeol. 26: 75-83.

Hoenen S. \& MARques M.D. 1998: Circadian patterns of migration of Strinatia brevipennis (Orthoptera: Phalangopsidae) inside a cave. Biol. Rhythm. Res. 29: 480-487.

Hoenen S. \& Marques M.D. 2000: Adaptação temporal e o ambiente cavernícola: uma interpretação. Biotemas 13(1): $129-144$.
Hoenen S., Schimmel M. \& Marques M.D. 2001: Rescuing rhythms from noise: a new method of analysis. Biol. Rhythm. Res. 32: 271-284.

Holsinger J.R. \& Culver D.C. 1988: The invertebrate cave fauna of Virginia and a part of eastern Tennessee: zoogeography and ecology. Brimleyana 14: 1-162.

Klaus U., Weinandy R. \& Gattermann R. 2000: Circadian activity rhythms and sensitivity to noise in the Mongolian gerbil (Meriones unguiculatus). Chronobiol. Int. 17: 137-145.

LAMPrecht G. \& Weber F. 1991: Spontaneous locomotion behaviour in cavernicolous animals: the regression of the endogenous circadian system. In Camacho A.I. (ed.): The Natural History of Biospeleology. Monografías del Museo Nacional de Ciencias Naturales, España, pp. 225-262.

LOHER W. 1979: The effect of male calling on female locomotor activity of Teleogryllus commodus. Beh. Ecol. Sociobiol. 5: 383-390.

LOHMANN M. \& ENRIGHT J.T. 1967: The influence of mechanical noise on the activity rhythms of finches. Comp. Biochem. Physiol. 22: 289-296.

MARQues M.D. \& Waterhouse J.M. 1994: Masking and the evolution of circadian rhythmicity. Chronobiol. Int. 11(3): 146-155.

MENAKeR M. \& EsKIN A. 1966: Entrainment of circadian rhythms by sound in Passer domesticus. Science 154: $1579-1581$.

Moeller K.A., Holley D.C., DeRoshia C.W., Mele G., Gott J., Okumura S., Winget C.M. \& Callahan P.X. 1992: Sound and its effects on circadian free-running periods of spraguedawley rats. FASEB J. 6(5): A 1831.

Moore-Ede M.C., Fuller C.A. \& Sulzman F.M. 1982: The Clocks That Time Us: Physiology of Circadian Timing System. Harvard University Press, Cambridge, Massachussetts, $448 \mathrm{pp}$.

Page T.L. 1989: Masking in invertebrates. Chronobiol. Int. 6(1): $3-11$.

Redlin U. \& Mrosovski N. 1999a: Masking of locomotor activity in hamsters. J. Comp. Physiol. (A) 184: 429-437.

Redlin U. \& Mrosovski N. 1999b: Masking by light in hamsters with SCN lesions. J. Comp. Physiol. (A) 184: 439-448.

Schimmel M. \& Paulssen H. 1997: Noise reduction and detection of weak, coherent signals through phase-weighted stacks. Geophys. J. Int. 130: 497-505.

Vilaplana J., Cambras T. \& Díez-Noguera A. 1995: Sound does not entrain the motor activity circadian rhythm of rats. Physiol. Behav. 58: 975-978.

Received October 19, 2004; revised and accepted June 27, 2005 